\title{
A Ecocrítica e o ensino interdisciplinar de Literatura e Ecologia: um estudo topofóbico-topofílico a partir de obras literárias regionais
}

\section{Ecocriticism and the interdisciplinary teaching of Literature and Ecology: a topophobic-topophilic study based on regional literary works}

\author{
Elisângela Campos Damasceno Sarmento ${ }^{1}$, Geraldo Jorge Barbosa de Moura²
}

\section{RESUMO}

Esta pesquisa tem como objetivo investigar a perspectiva Ecocrítica como uma ferramenta interdisciplinar para o ensino de Literatura e Ecologia, através das contribuições da Geografia Humanista e de outras áreas do conhecimento, a fim de sinalizar possíveis representações do sertanejo e do sertão a partir dos conceitos de topofobia e topofilia, além de utilizar o método da Análise do Discurso de Linha Francesa, levando em conta três obras literárias regionais, a saber: O Sertanejo (José de Alencar), O Quinze (Rachel de Queiroz) e Vidas Secas (Graciliano Ramos). Apresenta como principais resultados a constatação de que o ensino interdisciplinar de Literatura e Ecologia, mediante a Ecocrítica, possibilita uma aprendizagem mais profunda e significativa. Portanto, tal abordagem favorece a interdisciplinaridade, posto que busca dissolver as fragmentações, unindo as partes ao todo, com vistas a uma melhor compreensão das relações entre o homem e o ambiente.

Palavras-chave: Ecologia Humana; Educação; José de Alencar; Rachel de Queiroz; Graciliano Ramos.

\section{ABSTRACT}

This research aims to investigate the Ecocritical perspective as an interdisciplinary tool for the teaching of Literature and Ecology, through the contributions of Humanist Geography and other areas of knowledge, in order to signal possible representations of the countryside and of the backwoods from the concepts of topophobia and topophilia, in addition to using the method of French Discourse Analysis, taking into account three regional literary works, namely: The Countryside (José de Alencar), The Fifteen (Rachel de Queiroz) and Dried Lives (Graciliano Ramos). Its main results are the finding that the interdisciplinary teaching of Literature and Ecology, through Ecocriticism, enables deeper and more meaningful learning. Therefore, such an approach favors interdisciplinarity, since it seeks to dissolve fragmentations, uniting the parts to the whole, with a view to a better understanding of the relationship between the man and the environment.

Keywords: Human Ecology; Education; Jose de Alencar; Rachel de Queiroz; Graciliano Ramos.

${ }^{1}$ Instituto Federal do Piauí. Doutoranda do Programa de Pós-Graduação em Ecologia Humana e Gestão Socioambiental - PPGEcoH - UNEB - Juazeiro-BA, e-mail: elisceno@ifpi.edu.br. ${ }^{2}$ Universidade Federal Rural de Pernambuco. Programa de Pós-Graduação em Ecologia Humana e Gestão Socioambiental - UNEB; Programa de Pós-Graduação em Biodiversidade - UFRPE; Programa de Pós-Graduação em Biociência Animal - UFRPE, e-mail: geraldo.jbmoura@ufrpe.br. 


\section{INTRODUÇÃO}

Inicialmente, pontua-se que, de acordo com o crítico literário Antonio Candido (2009), o ensino de Literatura carece de uma perspectiva holística e interdisciplinar, uma vez que a arte da palavra (poesia, conto, romance) articula conhecimentos das mais variadas áreas do saber, tais como: História, Geografia, Biologia, Ecologia, Filosofia, Antropologia e Psicanálise.

Sobre esse aspecto, vale destacar os Parâmetros Curriculares Nacionais (1997), os quais frisam que a manifestação artística tem em comum com a ciência ou a filosofia o seu caráter de criação e inovação, suscitando imbricações com diversas formas de conhecimento. Em outras palavras, ciência e arte representam as formas de conhecimento do mundo que se renovam através dos tempos, construindo o percurso da história humana.

Nesse contexto, ressalta-se uma abordagem investigativa que surgiu no final dos anos 80 , nos EUA, cujo objetivo é estudar as correlações entre Arte (especialmente, Literatura) e Ecologia. Sob esse viés, emerge, no cenário acadêmico, a Ecocrítica que, segundo Greg Garrard (2006), suscita estudos interdisciplinares, congregando saberes e dando suporte a uma análise menos reducionista, uma vez que favorece a abrangência de perspectivas.

Considerando essa vastidão de imbricações com diversos ramos do conhecimento, também desponta, no panorama científico, a Ecologia, que adveio em 1866, a partir da publicação do livro intitulado Generelle Morphologie der Organismen, de Ernst Haeckel, e já, naquela época, sinalizava que essa ciência mantinha interações com inúmeras outras, destacando, pois, o seu caráter interdisciplinar.

Outrossim, a Ecocrítica configura-se como uma proposta interdisciplinar para o Ensino de Literatura e Ecologia, visto que dialoga com campos afins, como por exemplo, a Geografia Humanista. Partindo dessa premissa, devem ser salientados os contributos do geógrafo chinês YiFu Tuan (1982), quando busca analisar os comportamentos e as relações entre o ser humano e o lugar habitado.

Nessa lógica de investigação entre o sentimento humano e o local onde se vive, surgem dois elementos: o sertanejo e o sertão. Sendo assim, entre aquele e este, há relações, consoante Tuan (1982), topofóbicas (aversão) e topofílicas (apego). Isso ocorre devido aos contrastes da fitofisionomia da caatinga (ora seca, ora verde) conforme reverberam os estudos de José Maria Silva et al. (2004).

Para pesquisadores da Embrapa Semiárido, como Silva et al. (2004), o sertão do Nordeste brasileiro apresenta clima semiárido, vegetação com poucas folhas e adaptadas para os períodos de seca. Nessa época, quase todas as plantas perdem as folhas para diminuir a transpiração e evitar a perda de água armazenada. No inverno, devido à ocorrência de chuva, as folhas verdes e as flores voltam a brotar. 
Seguindo esse raciocínio, pondera-se que, como afirma Juares Thiesen (2008), o ensino interdisciplinar favorece a construção de novas posturas, desencadeando uma aprendizagem mais profunda e significativa. Dessa forma, as descobertas, provenientes da interdisciplinaridade enquanto ética docente, impulsionam a dissolução de fragmentações, integrando a arte à ciência, a emoção à razão, a realidade aos conhecimentos sistematizados.

Portanto, esta pesquisa tem como objetivo investigar a perspectiva Ecocrítica como uma abordagem interdisciplinar para o ensino de Literatura e Ecologia, através das contribuições da Geografia Humanista e de outras áreas do conhecimento, a fim de sinalizar possíveis representações do sertanejo e do sertão a partir dos conceitos de topofobia e topofilia e da análise do discurso de três obras literárias regionais, a saber: O Sertanejo (José de Alencar), O Quinze (Rachel de Queiroz) e Vidas Secas (Graciliano Ramos).

Ademais, o presente estudo parte da hipótese de que o ensino interdisciplinar de Literatura e Ecologia, mediante a Ecocrítica, permite uma aprendizagem mais abrangente e significativa, uma vez que busca eliminar as fragmentações e dicotomias, aproximando os saberes de variados ramos do conhecimento, com vistas a uma melhor compreensão das relações do homem com o ambiente.

\section{MATERIAL E MÉTODOS}

Considerando os elementos contextuais acima, sublinha-se que esta pesquisa assenta-se no livro O Sertanejo (1875/2002), de José de Alencar, bem como nas obras O Quinze (1930/2012), de Rachel de Queiroz e Vidas Secas (1938/2013), de Graciliano Ramos.

Desse modo, tendo em vista o direcionamento desta investigação, adotou-se o método da análise do discurso de linha francesa que, segundo o qual, conforme Michel Pêcheux (2006), não há discurso sem sujeito e não há sujeito sem ideologia. Nesses termos, o indivíduo é questionado em sujeito pela ideologia e é, assim, que a língua faz sentido.

Dessarte, Eni Orlandi (2012) corrobora a análise do discurso de linha francesa na qual considera as condições de produção em que as obras foram escritas, os contextos histórico-sociais do país e a história de vida dos autores, destacando essas características como muito relevantes para este estudo, visto que é através dessas ferramentas que será realizada a análise do discurso dos personagens das obras em questão. Além disso, na concepção de Orlandi (2012), há de se levar em conta os fatores histórico-sociais que envolveram a produção do discurso e também os sentidos implícitos e explícitos do texto.

Vale apontar, ainda, que, na análise do discurso, consoante Orlandi (2012), procura-se compreender a língua fazendo sentido, enquanto trabalho simbólico na relação do homem/personagem com a sua história e com as construções sociais. Dessa forma, o indivíduo/personagem norteia-se pela capacidade de significar e significar-se, validando tais 
sentidos no discurso do autor através das considerações de suas condições de produção, as quais compreendem, principalmente, o sujeito e a situação (contexto imediato e contexto amplo).

Nesse panorama, salienta-se que, para compreender as condições de produção no que tange aos sujeitos que enunciam - José de Alencar, Rachel de Queiroz e Graciliano Ramos - e a situação, foi realizada pesquisa bibliográfica relacionada aos autores e ao período histórico em que se inserem as obras $O$ Sertanejo, $O$ Quinze e Vidas Secas, além de ter sido considerada a ideologia intrínseca ao discurso produzido pelos sujeitos que falam nos textos consoante os estudos de Pêcheux (2006).

Ademais, destaca-se que foi adotada a perspectiva ecocrítica como mais um mecanismo de análise, tendo em vista que, conforme Garrard (2006), as relações entre Literatura e Ecologia são bastante relevantes para uma criteriosa e abrangente investigação em torno das relações ser humano-ambiente, considerando o universo interdisciplinar que permeia a dinâmica da vida em sociedade na imbricação com a cultura e a natureza.

Sendo assim, para construir o marco teórico deste artigo, foram acessadas diversas publicações, dentre elas: artigos científicos, localizados em periódicos nacionais e internacionais, que datam das primeiras décadas dos anos 2000, além de e-books, livros físicos de críticos literários brasileiros, bem como consultas que foram realizadas em sites da internet durante o mês de janeiro de 2022.

\section{RESULTADOS E DISCUSSÃO}

Analisar as relações homem-ambiente suscita uma visão interdisciplinar, posto que requer o diálogo com diversas áreas do conhecimento, haja vista a compreensão dos fenômenos socioculturais e simbólicos que estão implicados nesse processo. Relativamente às representações do sertanejo e do sertão, considera-se a ecocrítica como subsídio a um ensino interdisciplinar de Literatura e Ecologia, na mediação com a Geografia Humanista.

Em se tratando da Geografia Humanista, segundo Tuan (1982), é salutar o emprego da Literatura pelos geógrafos, pois há reflexões sobre a vida, a experiência humana e suas relações, oferecendo ferramentas à compreensão do espaço social. Sendo assim, para esta pesquisa, é indispensável a discussão de dois conceitos que foram propostos pelo geógrafo chinês, Yi-Fu Tuan: topofilia e topofobia.

Seguindo a linha de raciocínio de Tuan (1982), é a subjetividade (emoções, sentimentos), conectada ao meio, que aponta a possibilidade de definição de dois termos: topofilia que remete à familiaridade, apego ao lugar e topofobia, que traz uma significação inversa, pois fobia alude à aversão, tornando-se o lugar do medo, da repugnância. Dessa forma, essa subjetividade pode ser marcada tanto pela afeição quanto pelo desprezo, destacando essas emoções contraditórias e, ao mesmo tempo, coexistentes, que permeiam o universo humano. 
Nesse contexto, para um ensino interdisciplinar de Literatura e Ecologia a partir da ecocrítica, os conceitos de Tuan (1982) são valiosos para delinear as representações do sertanejo e do sertão através das análises dos discursos de três romances regionalistas: O Sertanejo (José de Alencar), O Quinze (Rachel de Queiroz) e Vidas Secas (Graciliano Ramos).

No que concerne à obra $O$ Sertanejo, conforme Sarmento e Moura (2021), assinala-se que esse romance evoca uma subjetividade, a qual é marcada pela topofilia . Essa percepção encontrase sinalizada nos trechos: "Esta imensa campina é o sertão de minha terra natal. Quando te tornarei a ver, sertão da minha terra, que atravessei há tantos anos na aurora serena e feliz da minha infância? Quando tornarei a respirar os teus perfumes agrestes?” (ALENCAR, 2002, p. 9).

Nesses termos, conforme Candido (2009), José de Alencar nasceu no sítio Alagadiço Novo, Mecejana-CE e só se mudou para o Rio de Janeiro com 10 anos. Logo, essas reminicências pueris acerca da terra natal apontam para um elemento autobiográfico, uma vez que o escritor soube captar a sensibilidade dos sertanejos, sendo mantido, mesmo distantes, o amor pelo solo onde nasceram, permanecendo as indeléveis reminiscências da infância que ficam gravadas na memória, despertando, assim, o desejo de retornar à terra natal e reviver essas lembranças.

Outrossim, a partir desses fragmentos, percebe-se um sentimento de pertencimento histórico ao lugar onde autor e personagem viveram uma infância "feliz e serena" (ALENCAR, 2002, p. 9) em meio à exuberância e à biodiversidade da paisagem sertaneja, contrariando, assim, descrições hegemônicas, como por exemplo, chão rachado e terra inóspita, parafraseando, apenas, algumas expressões utilizadas por escritores, como Euclides da Cunha, na obra Os Sertões.

Retomando a ideia de felicidade, trazida pelo sentimento de pertencimento histórico, salienta-se que essa noção corrobora a tese de Sigmund Freud (1900), quando afirma que a felicidade é a realização de um desejo pré-histórico, ou seja, antigo. Por isso, segundo a psicanálise freudiana, dinheiro não traz felicidade, pois uma criança não deseja ter dinheiro. Desse modo, a alusão que o adulto faz a sua infância, seja o local físico ou as pessoas e acontecimentos, representa uma demanda do homem sempre acompanhada de muita satisfação, quando realizada.

Em se tratando da imagem negativa e hegemônica do sertão, reitera-se que essa caracterização, segundo Josemar Martins (2006), foi difundida pelas elites coloniais e, assim, a caatinga ficou conhecida como uma região inóspita, de vegetação seca. Em contraposição, outras correntes vêm se afirmando, como a perspectiva da decolonialidade (MIGNOLO, 2010, p. 15) que valoriza as potencialidades de grupos e regiões que foram excluídos historicamente, como os sertanejos e o sertão, criando, assim, a subversão de um não-dito nativista e sertanista.

Retomando $O$ Sertanejo, realça-se que, embora o narrador apresente, na maioria dos trechos, um amor à sua terra natal, não deixa de relatar, também, a ambivalência da paisagem: "ora seca e triste, ora alegre e poética" (ALENCAR, 2002, p. 14) conforme os excertos: "A chapada tinha o aspecto triste que tomam aquelas regiões na seca. Dir-se-ia que por aí passou o fogo e consumiu toda a verdura, que é o sorriso dos campos na chuva" (ALENCAR, 2002, p. 14). 
Ainda ressaltando essa dualidade da paisagem, que é típica da Caatinga, apresenta-se o excerto: "Estes ares, em outra época povoados de pássaros, agora ermos e mudos como a terra, são apenas cortados pelo voo dos urubus que farejam a carniça” (ALENCAR, 2002, p. 15). Aqui se mostram dois momentos de percepção do sertão: um, repleto de vida, marcado pelo canto dos pássaros - topofilia - atração pelo lugar; e o outro, com a presença da morte, num ambiente inóspito, permeado de silêncio e decomposição - topofobia - repulsa ao lugar.

Historicamente, segundo Martins (2006), as narrativas sobre o sertão, provindas do Sul e Sudeste, salientam um dos aspectos da Caatinga: a fisionomia seca e, portanto, sem potencial de desenvolvimento. Por isso, perpassou-se a imagem hegemônica de exclusiva pobreza e miséria. Entretanto, a Literatura, seja ela artística ( $O$ Sertanejo) ou contra-hegemônica, descortina o outro aspecto da Caatinga: viva, rica e abundante, que precisa ganhar visibilidade no cenário nacional.

Ademais, infere-se que as alterações do ambiente moldam a subjetividade do sertanejo. Desse modo, as modificações da paisagem (árida, seca para verde e exuberante) determinam os sentimentos do sertanejo, ou seja, o seu universo de emoções, marcado por sensações positivas (bem-estar, alegria) ou negativas (tristeza, solidão, morbidez). Essa constatação pode ser reverberada no trecho:

Quem pela primeira vez percorre o sertão nessa quadra, depois de longa seca, sente confranger-se-lhe a alma em face dessa inanição da vida, desse holocausto da terra. É mais fúnebre do que um cemitério, um vasto jazigo de uma natureza extinta e o sepulcro da criação (ALENCAR, 2002, p. 16).

Analogamente, essas sensações - positivas ou negativas -, em face das transformações da paisagem do semiárido, podem ser associadas à bivalência das pulsões (de vida e de morte), discutidas por Freud (1915a, 1915b), e a dualidade (cooperação e competição), exposta por Charles Darwin (1981). Nesse viés, diante da escassez de recursos, em face das adversidades provenientes de longos períodos de estiagem, tanto o ambiente como os sertanejos absorvem as emoções negativas, desencadeando a pulsão de morte e o espírito competitivo, a fim de que sobrevivam em meio a uma caatinga seca e a uma vida plasmada de dores, perdas e privações.

Dessa maneira, na obra em exame, evidencia-se que, embora os sertanejos estejam imersos num ambiente árido em grande parte do ano, mostram-se apegados à terra onde nasceram, revelando um profundo sentimento de pertencimento ao lugar - topofilia, despertando uma relação subjetiva com o ambiente onde viveram e com as paisagens com as quais conviveram, construindo, assim, laços afetivos com o território.

Esse cenário pode ser constatado nos trechos: "E ela experimentava um indizível prazer, como se a terra de seu berço lhe abrisse os braços e a estivesse apertando ao seio e cobrindo-lhe de beijos" (ALENCAR, 2002, p. 19). Conforme Jan Simon Hutta (2020), os territórios são, inerentemente, afetivos e essa dimensão simbólica tem sido tratada através de noções como "topofilia", o que enfatiza o elo entre as pessoas e um lugar, assim como ocorre nessa obra. 
Nesse sentido, Rogério Haesbaert (2004) corrobora essa tendência dos territórios afetivos, quando afirma que, frequentemente, o termo territorialidade tem sido utilizado para enfatizar a apropriação subjetiva do território e a construção de uma identidade territorial através de registros simbólicos e topofílicos. Portanto, na obra em questão, o discurso topofílico se sobressai em relação ao topofóbico.

Considerando a discussão ora exposta, verifica-se que a Ecocrítica (Literatura-Ecologia) possibilita um ensino interdisciplinar, uma vez que a análise do discurso da obra $O$ Sertanejo, de José de Alencar, dialoga com outras áreas do saber, como por exemplo, Geografia, História, Antropologia, Psicanálise e Biologia, favorecendo, assim, uma aprendizagem profunda e significativa.

Por conseguinte, segundo Arlindo Philippi Júnior e Valdir Fernandes (2015), a prática da interdisciplinaridade não pretende negar os saberes disciplinares, mas complementá-los e ampliálos. Essa conjunção de conhecimentos é que vai possibilitar, na prática, a efetivação da complexidade do pensamento, dando conta dos fenômenos e da ampliação das experiências teórico-práticas interdisciplinares, que envolvem múltiplos saberes.

Quanto à obra $O$ Quinze, consoante Sarmento e Moura (2022), destaca-se que, nesse romance, são predominantes as expressões topofóbicas voltadas ao sertão, mas não são imagens de repugnância ao lugar, por não fazer parte dele, por não carregar consigo o sentimento de pertencimento como ocorre na obra de Euclides da Cunha Os Sertões ("terra ignota, de natureza torturada" - CUNHA, 2009, p. 29), o que há é a denúncia de uma caatinga abandonada pelo Governo que adota uma política de repulsa e não um projeto de convivência com o semiárido.

Para expressar esse tom de crítica social a uma caatinga desolada e carente de investimentos que propiciem a convivência do sertanejo com a seca, seguem termos e orações, retirados do segundo capítulo:

Estrada vermelha e pedregosa, orlada pela galharia negra da caatinga morta. Folhas secas no chão. Verde, na monotonia cinzenta da paisagem, só algum juazeiro ainda escapou à devastação da rama; E o chão, que em outro tempo a sombra cobria, era uma confusão de galhos secos (QUEIROZ, 2012, p. 15).

Essas passagens coadunam, assim, o caráter topofóbico do sertão em tempos de estiagens prolongadas.

Ademais, é oportuno sublinhar que, consoante Edilane Silva et al (2014), no artigo intitulado Topofobia e topofilia em "A Terra", de "Os Sertões": uma análise ecocrítica do espaço Sertanejo Euclidiano, reverbera-se a perspectiva topofóbica euclidiana no tocante à percepção da caatinga, uma vez que o escritor, oriundo da região Sudeste, deixa emergir uma visão de repulsa ao semiárido nordestino, apresentando, pois, uma narrativa preconceituosa como se a fitofisionomia da caatinga fosse, exclusivamente, seca, sem vida e, portanto, inóspita.

Nesse ínterim, salienta-se que, mesmo diante de eloquentes críticas voltadas ao abandono do sertão nordestino, como por exemplo na obra $O$ Quinze, de Rachel de Queiroz, somente, em 
1980, conforme o professor da UFRN, Roberto da Silva (2003), surgiram as primeiras pesquisas destinadas à área de sequeiro, com foco na necessidade de se conviver com a seca, mediante o desenvolvimento de tecnologias apropriadas ao homem do semiárido.

Retomando o enredo da obra em apreço, vale assinalar trechos que frisam o cenário angustiante da seca, bem como a porosidade emocional e de sina entre os animais e o sertanejo, absorvendo, pois, as características de ambos facilmente:

Chico Bento bateu os paus na porteira e foi caminhando devagar, atrás do lento caminhar do gado, que marchava à toa e pondo no pasto seco os olhos tristes, como numa agudeza de desesperança; Outras reses seguiam cabisbaixas, na mesma marcha pensativa; O marmeleiral esquelético, era tudo cinzento, o próprio leito das lagoas vidrara-se em torrões de lama ressequida; - Ô sorte, meu Deus! Comer cinza até cair morto de fome! (QUEIROZ, 2012, p. 18).

Outrossim, observando essa dramática descrição-narrativa, evidencia-se o aspecto trágico da cena, peculiaridade da autora, que, conforme Andrea Lobato e Eduardo Pereira (2011), apresenta uma atmosfera cíclica: "é caminhar, caminhar e se deparar com tudo seco, cinzento até morrer de fome" como um destino implacável e irrevogável. Dessa forma, em meio a essa tragédia humana, o ambiente é topofóbico.

Esse contexto dramático também aparece nas passagens: "Sem legume, sem serviço, sem meios algum, não havia de ficar morrendo de fome, enquanto a seca durasse" (QUEIROZ, 2012, p. 21); “- Que passagens! Tem de ir tudo é por terra, feito animal! Nesta desgraça quem é que arranja nada!" (QUEIROZ, 2012, p. 23). Desse modo, ratifica-se um ambiente adverso que suscita emoções topofóbicas, expulsando o homem do campo de seu lugar.

Nessa tônica, Rachel de Queiroz, na obra $O$ Quinze, denunciou as reduzidas e ineficazes políticas públicas destinadas ao sertão cearense, marcado pelas consequências da seca, que se tornou uma tragédia humana como se pode constatar nos excertos que se seguem: "De tarde, quando caminhavam com muita fome" (QUEIROZ, 2012, p. 34);

- Meu filho! Pelo amor de Deus! Você comeu mandioca crua? - Chico! Chico! Valha-me Nossa Senhora! O Josias se envenenou; a criança era só osso e pele: o relevo do ventre inchado formava quase um aleijão naquela magreza, esticando o couro seco de defunto (QUEIROZ, 2012, p. 35).

Para Nietzsche (1999), na tragédia humana, há forças opostas: a apolínea - uma estabilidade ilusória - que, na obra em apreço, é o menino Josias caminhar com os pais, mesmo com uma fome incontrolável, mas perto deles, sem pensarem na morte; e a dionisíaca, configurada pela embriaguez da realidade cruel, que é o estarrecimento da dor em face da morte da criança:"Lá se tinha ficado o Josias, na sua cova à beira da estrada" (QUEIROZ, 2012, p. 38).

E essa percepção dionisíaca é verossímil e perseguia a vida dos retirantes, pois retrata a realidade tal qual ela se apresenta: “- Ah! Minha rede! Ô chão duro dos diabos! E que fome!” (QUEIROZ, 2012, p. 32); "Só talvez por um milagre iam aguentando tanta fome, tanta sede, tanto sol"; "E se não fosse uma raiz de mucunã arrancada aqui e além, ou alguma batata-brava que a 
seca ensina a comer, teriam ficado todos pelo caminho." (QUEIROZ, 2012, p. 39). Dessarte, corrobora-se um ambiente adverso e repugnante, gerando sentimentos topofóbicos e, portanto, de tristeza e pavor pelo quadro de miséria, retratado pelos lugares por onde os retirantes passavam.

Abandonando esse cenário, a paisagem dá sinais de mudança com as primeiras chuvas e começa a ressurgir a esperança de dias melhores para o sertanejo, apresentando um ambiente topofílico: "Enfim caiu a primeira chuva de dezembro" (QUEIROZ, 2012, p. 73); "O pasto se enramava, a caatinga despontava toda em grelos verdes" (QUEIROZ, 2012, p. 78); "E tudo era verde. O borralho cinzento do verão vestira-se todo de esperança" (QUEIROZ, 2012, p. 79).

Entretanto, ainda existia a sombra da miséria para os que ficaram no campo e resistiram aos golpes da fome. Todavia, os raios da chuva inebriavam a possibilidade de breve fartura:

Carecia esperar que o feijão grelasse, enramasse, floreasse, que o milho abrisse as palmas, estendesse o pendão, bonecasse, e que ainda por muitos meses a mandioca aprofundasse na terra as raízes negras. Tudo isso era vagaroso, e ainda tinham que sofrer vários meses de fome (QUEIROZ, 2012, p. 79).

Isso posto, a obra $O$ Quinze cumpre a função de denúncia da realidade, tendo como temática primordial a seca, mas tocando em aspectos relevantes que permeiam essa tragédia, como por exemplo, o descaso do Governo e a resiliência do sertanejo, que sobrevive a uma saga de penúria, mas acreditando, ainda, na possibilidade de um futuro melhor. Sendo assim, em O Quinze, o discurso topofóbico é predominante na comparação com o topofílico.

Levando em conta o que foi exposto, observa-se que a Ecocrítica (Literatura-Ecologia) favorece a adoção de um ensino interdisciplinar, visto que a análise do discurso da obra $O$ Quinze, de Rachel de Queiroz, apresenta uma dinâmica de relações com outros ramos do conhecimento, como por exemplo, Geografia, História, Filosofia e Biologia, impulsionando, assim, uma amplitude de aprendizagens.

Logo, para Hilton Japiassu (1976), a pedagogia interdisciplinar busca o conhecimento em sua totalidade, abrangendo os saberes que convergem e/ou se complementam. Ivani Fazenda (2003) corrobora Japiassu (1976) quando defende que o ensino interdisciplinar se faz numa relação de reciprocidade e se configura como uma possibilidade de reflexão sobre o(s) saber(es), assim como a oportunidade de modificá-lo(s) e ampliá-lo(s). Concebido, assim, o ensino interdisciplinar é essencial a uma aprendizagem que se distancie da superficialidade.

Relativamente à obra Vidas Secas, sinaliza-se um relevo aos sentimentos topofóbicos do sertanejo na relação com o lugar conforme o trecho: "Os infelizes tinham caminhado o dia inteiro, estavam cansados e famintos" (RAMOS, 2013, p. 6). Sendo assim, observa-se a desolação dos retirantes (“infelizes", “cansados", "famintos”). Logo, essa situação adversa se mistura com o cenário nefasto em que se encontravam: "rio seco"; "galhos pelados da caatinga rala"; "a caatinga estendia-se com um vermelho salpicado de manchas brancas que eram ossadas" (RAMOS, 2013, p. 6). Diante disso, esboça-se um cenário topofóbico, de repulsa ao lugar e de imagens fúnebres que remetem a um quadro de morte e de degradação. 
Outrossim, delineia-se um contexto dionisíaco (topofóbico) que, segundo Nietzsche (1999), representa a realidade cruel e trágica com a qual o sertanejo se depara em meio às adversidades ambientais e socioeconômicas: sem comida, sem água, sem nada. Sobre essa situação de penúria, assinala-se o excerto a seguir:

Fabiano tomou a cuia, desceu a ladeira, encaminhou-se ao rio seco, achou no bebedouro dos animais um pouco de lama. Cavou a areia com as unhas, esperou que a água marejasse e, debruçando-se no chão, bebeu muito; Encheu a cuia, ergueu-se lento, para não derramar a água salobra; Pôs a cuia no chão, escorou-a com pedras, matou a sede da família (RAMOS, 2013, p. 7).

Diante desse quadro, fica explícita a paisagem topofóbica, que encaminha o bichohomem-retirante a uma condição subumana.

Sob esse viés, em situação de desolação, aflora-se a "pulsão de morte", o desejo de destruição para se livrar da dor. Nessa perspectiva, consoante Freud (1915a, 1915b), há duas pulsões que permeiam a essência humana: a de vida e a de morte. Essa dualidade faculta ao ser humano lidar com as diversas facetas da vida. Nesse sentido, o espírito combativo do sertanejo associa-se a uma "pulsão de morte" que eclodiu no íntimo de "Fabiano" numa resposta dramática ao contexto adverso do retirante, tendo em vista a sobrevivência em meio à absoluta miséria.

Ademais, destaca-se que é essa mesma "pulsão de morte" que desencadeia a força e a coragem do sertanejo, características indispensáveis à superação das adversidades, como a fome e a sede, em face dos longos períodos de estiagem. Desse modo, as marcas da miséria não são, tão somente, físicas ou orgânicas, mas, principalmente, morais e emocionais como ratificam os fragmentos a seguir:

— Fabiano, você é um homem, exclamou em voz alta; E, pensando bem, ele não era homem: era apenas um cabra ocupado em guardar coisas dos outros; como vivia em terra alheia, cuidava de animais alheios, descobria-se, encolhiase na presença dos brancos e julgava-se cabra (RAMOS, 2013, p. 9).

E essa inexistência de direitos desencadeia a impossibilidade de o retirante galgar outros caminhos. Dessa maneira, o sertanejo sente-se fadado a uma predestinação de miséria como descreve o excerto: "Tinha obrigação de trabalhar para os outros. Ninguém tinha culpa de ele haver nascido com um destino ruim. Podia mudar a sorte? Se lhe dissessem que era possível melhorar de situação, espantar-se-ia" (RAMOS, 2013, p. 33). Nesse ínterim, imerso em um ambiente topofóbico, infere-se que o sertanejo não consegue se desarraigar do seu destino de privações, sem dignidade para si e para a sua família, sendo tratado com inferioridade.

De acordo com Fabiano, personagem da obra Vidas Secas, para suportar a miséria, os sertanejos têm de se habituar a ser como bichos e a se identificar com eles: "Sim senhor, um bicho, capaz de vencer dificuldades"; "Vivia longe dos homens, só se dava bem com animais" (RAMOS, 2013, p. 9). Dessa forma, desenvolver a resistência para enfrentar a desolação é fundamental para sobreviver na penúria. 
Assinala-se que, embora o sertanejo estivesse trabalhando e garantindo o sustento de sua família em terra alheia, as sombras de uma possível seca o atormentavam como uma tragédia que se pré-anuncia:

Se a seca chegasse, não ficaria planta verde. Chegaria, naturalmente. Sempre tinha sido assim, desde que ele se entendera. E antes de se entender, antes de nascer, sucedera o mesmo - anos bons misturados com anos ruins. A desgraça estava em caminho, talvez andasse perto. Nem valia a pena trabalhar - ela se avizinhando a galope, com vontade de matá-lo (RAMOS, 2013, pp. 10-11).

Sendo assim, as secas sazonais são comuns no sertão nordestino e evidenciam cenários topofóbicos que suscitam uma miséria iminente.

Partindo dessa premissa, tal quadro topofóbico representa uma crítica social, denunciando a miséria do retirante. Nesse cenário, um fato curioso é a obsessão do "menino mais velho" em descobrir o significado do vocábulo inferno conforme apontam os trechos: "Ele nunca tinha ouvido falar em inferno. Pediu informações à Sinhá Vitória que aludiu a certo lugar ruim demais, mas o menino não se conformou com a resposta” (RAMOS, 2013, p. 21). Na realidade, a família de retirantes vivencia um "inferno" metaforicamente, uma vez que, em meio à seca, encontra-se numa paisagem adversa que suscita emoções topofóbicas.

Entretanto, a fitofisionomia da caatinga não é, permanentemente, seca. Há épocas de chuva, o que evoca sentimentos duais na relação com essa paisagem: ora topofóbicos, ora topofílicos. Acerca dessa constatação, destacam-se os excertos: "Por enquanto a inundação crescia. Não havia o perigo da seca imediata, que aterrorizara a família" (RAMOS, 2013, p. 23); "Pensou com um arrepio na seca, na viagem medonha que fizera em caminhos abrasados, vendo ossos e garranchos. Afastou a lembrança ruim, atentou naquelas belezas” (RAMOS, 2013, p. 28).

Por conseguinte, reitera-se que, em situação de escassez de recursos (seca), o cenário e os sentimentos aflorados são topofóbicos. Em contrapartida, na abundância de tais recursos (chuvas constantes), a paisagem se transforma, tornando-se topofílica, e as emoções modificamse, dando lugar à esperança de dias melhores.

Com base no que foi discutido acima, realça-se que a Ecocrítica (Literatura-Ecologia) permite um ensino interdisciplinar, posto que a análise do discurso da obra Vidas Secas, de Graciliano Ramos, articula saberes que se conectam a vários campos do conhecimento, como por exemplo, Geografia, História, Filosofia, Psicanálise e Biologia, desencadeando, assim, uma série de descobertas que se justapõem, formando novas aprendizagens, mais profundas e significativas.

Nesse caminho, segundo Nelson Maldonado-Torres (2016), a interdisciplinaridade sugere uma atitude decolonial, pois, nesses paradigmas, não há a dicotomia superior/inferior; na visão de Paulo Freire (1978), suscita a dialogicidade na educação pela integração de saberes; conforme Jean Paul Bronckart e Anna Rachel Machado (2009), apresenta um interacionismo sociodiscursivo, eliminando os isolamentos; consoante Thomas Kuhn (1989), é uma revolução científica no interior da ciência, promovendo um novo pensamento científico e, por fim, para 
Fritjof Capra (1982), é uma visão sistêmica da vida, que promove a ética e a sustentabilidade planetária. Daí, a grande importância de um ensino interdisciplinar de Literatura e Ecologia a partir da Ecocrítica, haja vista as complexas relações que envolvem o homem e o ambiente.

\section{CONSIDERAÇÕES FINAIS}

Diante do exposto, a proposta de uma abordagem interdisciplinar para o ensino de Literatura e Ecologia, mediada pela perspectiva ecocrítica e pela análise do discurso das obras literárias regionalistas: O Sertanejo, O Quinze e Vidas Secas, caracteriza-se como uma alternativa à educação brasileira, com vistas à superação do isolamento disciplinar das especializações e à busca incessante pela qualidade das instituições escolares.

Desse modo, esta pesquisa pretendeu demonstrar os contributos da interdisciplinaridade como expressão de uma nova racionalidade científica que articula objetividade e subjetividade e suscita o diálogo entre os diversos saberes, promovendo um pensamento holístico, que une as partes ao todo e o todo às partes, eliminando, assim, as dicotomias inférteis que reduzem as possibilidades de uma reflexão sistêmica e ética sobre as interações entre o homem e o ambiente.

Nesse sentido, visando a uma melhor compreensão do universo de articulações entre o homem e o ambiente, a Geografia Humanista foi de suma relevância ao lançar mão de dois conceitos fundamentais para a análise dos sentimentos humanos com o lugar habitado: topofilia e topofobia. Assim, tornou-se possível delinear as representações do sertanejo e do sertão à luz da ecocrítica na interlocução com inúmeras áreas do conhecimento, como por exemplo, História, Psicanálise, Filosofia, Antropologia e Biologia.

Portanto, o viés interdisciplinar agrega um imensurável valor ao ensino e à educação de um modo geral, impulsionando os seres humanos a uma aprendizagem profunda, significativa e de qualidade. Ademais, o paradigma da interdisciplinaridade favorece a adoção de uma ética para a vida, suscitando a desconstrução de preconceitos e desencadeando atitudes que valorizam as relações integrais, sem dicotomias ou hierarquias.

\section{REFERÊNCIAS}

ALENCAR, J. de. O Sertanejo. São Paulo: José Olympio, 2002.

BRASIL. Secretaria de Educação Fundamental. Parâmetros Curriculares Nacionais: arte. Brasília: MEC/SEF, 1997.

BRONCKART, J. P.; MACHADO, A. R. (Re-)configurações do trabalho do professor construídas nos e pelos textos: a perspectiva metodológica do grupo ALTER-LAEL. In: Cristóvão, V. L. P.; Tardelli-Abeu, L. S. (org.). Linguagem e educação: o trabalho do professor em uma nova perspectiva. Campinas: Mercado de Letras, 2009. pp. 31-77.

CANDIDO, A. A Personagem de Ficção. São Paulo: Perspectiva, 2009. 
CAPRA, F. O ponto de mutação: a ciência, a sociedade e a cultura emergente. São Paulo: Cultrix, 1982.

CUNHA, E. da. Os Sertões. São Paulo: Ediouro, 2009.

DARWIN, C. Descent of Man. Princeton: Princeton University Press, 1981.

FAZENDA, I. A avaliação na pós-graduação sob a ótica da interdisciplinaridade. In: QUELUZ, A. G. (Org.). Interdisciplinaridade: formação de profissionais da educação. São Paulo: Pioneira Thomson Learning, 2003. pp. 23-28.

FREIRE, P. Pedagogia do Oprimido. Rio de Janeiro: Paz e Terra, 1978.

FREUD, S. A Interpretação dos Sonhos. In: FREUD, S. Obras Completas. Buenos Aires: Amorrortu, v. IV-V, pp. 65-100, 1900.

FREUD, S. O Inconsciente. In: FREUD, S. Obras Completas. Rio de Janeiro: Imago, 1915a, pp. 183-233.

FREUD, S. Os instintos e suas vicissitudes. In: FREUD, S. Obras Completas. Rio de Janeiro: Imago, 1915b, pp. 129-162.

GARRARD, G. Ecocrítica. Brasília: Universidade de Brasília: 2006.

HAESBAERT, R. O mito da desterritorialização: do "fim dos territórios" à multiterritorialidade. Rio de Janeiro: Bertrand Brasil, 2004.

HUTTA, J. S. Territórios afetivos: cartografia do aconchego como uma cartografia de poder. Revista Caderno Prudentino de Geografia. Presidente Prudente, Número Especial "Múltiplas e Microterritorialidades nas Cidades", pp. 63-89, jun., 2020.

JAPIASSU, H. Interdisciplinaridade e patologia do saber. Rio de Janeiro: Imago, 1976.

KUHN, T. A estrutura das revoluções científicas. São Paulo: Perspectiva, 1989.

LOBATO, A. T. M.; PEREIRA, E. O. A seca e a narrativa do trágico em O Quinze de Rachel de Queiroz. Revista Garrafa 24, Rio de Janeiro, v. 9, n. 27, pp. 1-17, 2011.

MALDONADO-TORRES, N. Transdisciplinaridade e decolonialidade. Soc. estado. [online], v. 31, n. 1, pp. 75-97, 2016. Disponível em: https://bit.ly/2PmtsTD. Acesso em: 21 jan. 2022.

MARTINS, J. da S. Tecendo a rede: notícias críticas do trabalho de descolonização curricular no Semi-Árido Brasileiro e outras excedências 2006. 344 f. Tese (Doutorado em Educação) Universidade Federal da Bahia, Salvador, 2006.

MIGNOLO, W. D. Aiesthesis Decolonial. Calle, v. 4, n. 4, pp. 10-25, enero/junio, 2010.

NIETZSCHE, F. O nascimento da tragédia ou helenismo e pessimismo. São Paulo: Companhia das Letras, 1999.

ORLANDI, E. P. Análise de discurso: princípios e procedimentos. Campinas, SP: Pontes/UNICAMP, 2012.

PÊCHEUX, M. O discurso: estrutura ou acontecimento. Campinas: Pontes, 2006. 
PHILIPPI JR, A.; FERNANDES, V. Práticas da Interdisciplinaridade no Ensino e na Pesquisa. Barueri, SP: Manole, 2015.

QUEIROZ, R. de. O Quinze. Rio de Janeiro: Editora José Olympio, 2012.

RAMOS, G. Vidas Secas. Rio de Janeiro: Editora Record, 2013

SARMENTO, E. C. D.; MOURA, G. J. B. de. Topofobia e topofilia em $O$ Quinze: uma análise ecocrítica da obra de Rachel de Queiroz. Revista Geografia, Londrina, v. 31, n, 1, pp. 75-94, jan., 2022.

SARMENTO, E. C. D.; MOURA, G. J. B. de. Topofilia e topofobia em O Sertanejo: uma análise ecocrítica da obra alencarina. Revista Caderno de Geografia, Belo Horizonte, v. 31, n. 67, pp. 1078-1094, 2021.

SILVA, R. M. A. da. Entre dois paradigmas: combate à seca e convivência com o semiárido. Revista Sociedade e Estado. Brasília, v. 18, n. 1/2, pp. 361-385, 2003.

SILVA, E. F. da; COSTA, É. M. A.;.MOURA, G. J. B. de. Topofobia e topofilia em "A Terra", de "Os Sertões": uma análise ecocrítica do espaço Sertanejo Euclidiano. Revista Sociedade \& Natureza, Uberlândia, v. 26, pp. 253-260, 2014.

SILVA, J. M. C. da; TABARELLI, M.; FONSECA, M. T. da. Áreas e ações prioritárias para a conservação da biodiversidade na caatinga. In: SILVA, J. M. C. da; TABARELLI, M.;

FONSECA, M. T. da (Org). Biodiversidade da Caatinga: áreas e ações prioritárias para a conservação. Brasília (DF): MMA/UFPE/Conservation International - Biodiversitas - Embrapa Semiárido, 2004, pp. 349-374.

THIESEN, J. S. A interdisciplinaridade como um movimento articulador no processo ensinoaprendizagem. Revista Brasileira de Educação, Rio de Janeiro, v. 13. n. 39, pp. 545-598, 2008.

TUAN, Y. Geografia Humanista. In: CRISTOFOLETI, A. (Org.) Perspectivas da Geografia. São Paulo: DIFEL 1982. pp. 165-193.

\section{Recebido em: 10/01/2022}

Aprovado em: 12/02/2022 